\title{
Mapping Rare Erythrocyte Phenotypes in Morocco: A Tool to Overcome Transfusion Challenges
}

\author{
A. Benahadi, ${ }^{1,2}$ S. Boulahdid,,${ }^{1,2}$ B. Adouani, ${ }^{1,2}$ A. Laouina, ${ }^{1,2}$ A. Mokhtari, ${ }^{2}$ A. Soulaymani, ${ }^{2}$ \\ K. Hajjout, ${ }^{1}$ M. Benajiba, ${ }^{1}$ and R. Alami ${ }^{1}$ \\ ${ }^{1}$ Centre National de Transfusion Sanguine, Rue Lamfadal Charkaoui, Madinat Al Irfane, BP 180, Rabat, Morocco \\ ${ }^{2}$ Laboratoire de Génétique et de Biométrie, Faculté des Sciences, University Ibn Tofaill, Kenitra, Morocco \\ Correspondence should be addressed to R. Alami; raoufalami@yahoo.com
}

Received 28 November 2013; Revised 28 January 2014; Accepted 6 February 2014; Published 12 March 2014

Academic Editor: Arturo Pereira

Copyright (C) 2014 A. Benahadi et al. This is an open access article distributed under the Creative Commons Attribution License, which permits unrestricted use, distribution, and reproduction in any medium, provided the original work is properly cited.

The aim of this research is to search for the distribution of blood groups in all the regions of Morocco. This study, done for the first time, aimed to provide the frequency of the Rhesus system and Kell (K) in more than 55000 blood donors from nine different regions around the country. In addition, the frequency of the Cellano, Duffy, Kidd, and MNS blood antigens was searched for 500 blood donors from the Rabat's region. Frequency of blood donors with rare blood groups was characterized for the first time in the country and compared to results found from other populations.

\section{Introduction}

Blood group phenotypes have been used for several applications as for blood transfusion practices and population genetic studies [1-3].

In Morocco, no study has identified yet the distribution and frequency of different blood groups. In this perspective we tried to identify the Rhesus phenotypes in nine different regions spanning the whole country. We have also conducted a study to determine the frequencies of the $\mathrm{k}$ (cellano), Fya, Fyb, Jka, Jkb, S, and s antigens in blood donors (BD) from the Rabat region.

\section{Materials and Methods}

Fifty-five thousand six hundred and thirty $(N=55630) \mathrm{BD}$ who gave blood in nine different regions were phenotyped for the following Rhesus blood antigen D, C, E, c, and e. In addition, from the CRTS Rabat, we phenotyped $513 \mathrm{BD}$ in the $S$ and $s$ antigens from the MNS system, Fya and Fyb antigens from the Duffy system, Jka and Jkb antigens from the Kidd system, and k (cellano) antigen from the Kell system.

For the determination of Rhesus and Kell typing, we used the OLYMPUS PK7300 Automated System and/or microplates by standard hemagglutination test using commercial monoclonal antisera IgM anti-D, anti-C, anti-c, anti$\mathrm{E}$, anti-e, and anti-K monoclonal antibodies (Diagast). All samples that showed negative agglutination with monoclonal/polyclonal IgM/IgG anti-D and the Fy (a-, b-) phenotype were confirmed using Coombs' test. Fya, Fyb, Jka, Jkb, S, $\mathrm{s}$, and $\mathrm{k}$ (cellano) antigens were typed by commercially prepared polyclonal antisera (Seraclone) with microplates methods for $\mathrm{S}$ antigen and by hemagglutination in gel cards (BIORAD,ORTHO/BLISS, INVITROGEN) for other antigens.

Positive and negative control cells and Coombs' control cells were used for quality controls.

The allele frequencies were calculated using the gene counting method, which was described by Mourant et al. in 1976 [4].

Statistical analysis was carried out using Microsoft Excel and the program PASTE [5].

\section{Results and Discussion}

We characterized the Rhesus antigens distribution in 55630 randomly chosen BD from 9 regions, representing different ethnic groups of Morocco. 


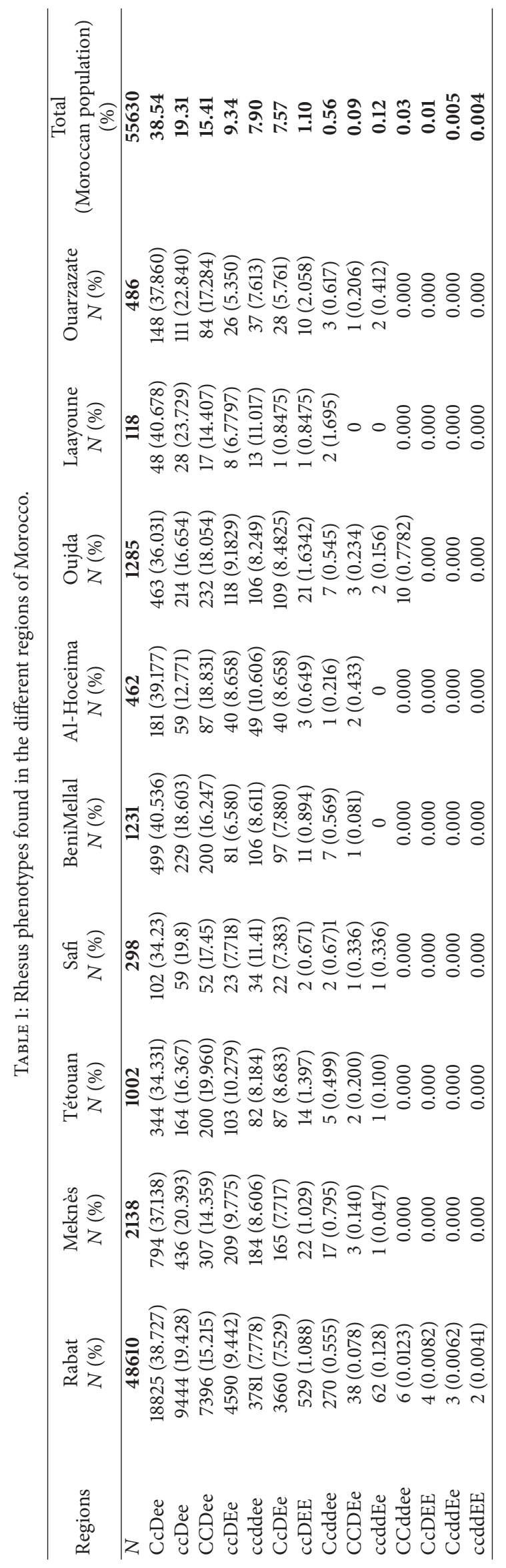


The Rhesus antigens frequencies found were as follows: e (89.45\%), D (70.65\%), c (60.58\%), C (38.54\%), and E (9.59\%). The observed phenotypes distributions are summarized in Table 1. The CcDee phenotype was represented in all the studied regions. Its frequency ranged from $34.23 \%$ in Safi to $40.67 \%$ in the south of the country at Laayoune. By contrast, three phenotypes (CcDEE, CcddEe, and ccddEE) were characterized only in Rabat BD with the lowest frequency in the country $(0.0082 \%, 0.0062 \%$, and $0.0041 \%$, resp.).

Little data are available regarding the frequencies of the blood group antigens other than $\mathrm{ABO}$ and $\mathrm{RhD}$ in the Moroccan population. In this study, we examined the composition of RBC antigens in Moroccan BD. It is the first study in Morocco that involved such large number of $\mathrm{BD}(N=$ 55630 ). The $\mathrm{D}$ antigen is present in $70 \%$ of the $\mathrm{BD}$ population, thus showing an intermediate prevalence between those found in the African and European continents [6-8]. The e antigen (89\%) and $c$ antigen (61\%) are most frequent in Morocco; this is concordant with Tagny et al.s, 2010 [9].

The most common Rhesus haplotypes in Morocco are DCe, followed by Dce and then by dce, respectively, found at $0.38,0.34$, and 0.28 . This prevalence is similar to our neighbor Algerians [10] and Tunisians [11]. While in Mauritania and in Sub-Saharan Africa, it is the Dce that shows the highest prevalence $[6,7,12]$.

In addition, Principal Component Analysis showed a clear evidence of a north-to-south gradient for some Rhesus phenotypes. In fact the DCcEe, CCDee, and ccDEe are linked to the north regions (Tétouan, Oujda, and Al-Hoceima) while the Dccee is associated with the south provinces (Laayoune and Ouarzazate). This gradient was also found in a previous study by our group for the D antigen [1].

Other system (Kell, MNS, Duffy, and Kidd) phenotype frequencies showed that out of 513 Rabat's blood donors, only one donor $(0.19 \%)$ was homozygote for the K. Cellano represented $99.80 \%$. A north-to-south gradient was observed for the Kell antigen.

The $\mathrm{S}$ and $\mathrm{s}$ antigens were positive in $43.1 \%$ and $91.2 \%$, respectively. Fy $(\mathrm{a}-\mathrm{b}+)$ was the most common phenotype seen in about $42 \%$ of the studied subjects. The Duffy null or Fy $(\mathrm{a}-\mathrm{b}-)$ phenotype was observed in $11.11 \%$. This latter phenotype is referred to in the African population as discussed by different authors [7, 13, 14].

For the Kidd system, about half (49.5\%) of our BD have the Jk $(a+b+)$, as found in the European population [15]. The $\mathrm{Jk}(\mathrm{a}-\mathrm{b}-)$ was not found in the studied population. Jka and $\mathrm{Jkb}$ antigens were recorded in $84.21 \%$ and $65.3 \%$ of subjects, respectively (Table 2 ).

\section{Conclusion}

Since the current practice of providing compatible blood to patients in Morocco is still relaying on blind cross-matching of available red blood cell units, we initiated this study to map the distribution of the blood groups around Morocco, especially for better management of red cell unit delivery to highly alloimmunized patients.

The main result found here illustrated that the Moroccan population shares phenotypes with Sub-Saharan Africa and
TABLE 2: Kell, MNS, Duffy, and Kidd blood group frequencies (\%) compared with other ethnic groups.

\begin{tabular}{lccc}
\hline Phenotypes & Our donors (\%) $(N)$ & Caucasians [16] & Blacks [16] \\
\hline K+k- & $0.19(\mathbf{1})$ & 0.2 & Rare \\
K+k+ & $9.16(\mathbf{4 7})$ & 8.8 & 2 \\
K-k+ & $90.64(\mathbf{4 6 5})$ & 91 & 98 \\
S+s- & $8.77(\mathbf{4 5})$ & 11 & 3 \\
S+s+ & $34.31(\mathbf{1 7 6})$ & 44 & 28 \\
S-s+ & $56.92(\mathbf{2 9 2})$ & 45 & 69 \\
Fy (a+b-) & $19.30(\mathbf{9 9})$ & 17 & 9 \\
Fy (a+ b+) & $27.88(\mathbf{1 4 3})$ & 49 & 1 \\
Fy (a- b+) & $41.72(\mathbf{2 1 4})$ & 34 & 22 \\
Fy (a- b-) & $11.11(\mathbf{5 7})$ & Very rare & 68 \\
Jk (a+b-) & $34.70(\mathbf{1 7 8})$ & 28 & 57 \\
Jk (a+b+) & $49.51(\mathbf{2 5 4})$ & 49 & 34 \\
Jk (a- b+) & $15.79(\mathbf{8 1})$ & 23 & 9 \\
Jk (a- b-) & 0 & Very rare & Very rare \\
\hline
\end{tabular}

European populations, and a clear evidence of a north-tosouth gradient for some Rhesus phenotypes.

Some particularities were also found as the higher frequency of " $\mathrm{e}$ " antigen blood group and the Fy $(\mathrm{a}-\mathrm{b}-)$ which was represented at a significant frequency (11.1\%).

\section{Conflict of Interests}

The authors declare that there is no conflict of interests regarding the publication of this paper.

\section{Authors' Contribution}

A. Benahadi, S. Boulahdid, B. Adouani, A. Laouina, K. Hajjout, M. Benajiba, and R. Alami were supported by the CNTS, Ministry of Health. A. Soulaymani and A. Mokhtari were supported by Ibn Tofail University, Kenitra. A. Benahadi collected thedata and performed the research. S. Boulahdid, B. Adouani and A. Laouina collected the data. A. Soulaymani and A. Mokhtari analyzed the data, K. Hajjout and M. Benajiba contributed reagents/materials/analysis tools, and R. Alami designed the research study, performed the research, and validated the paper.

\section{Acknowledgments}

The authors would like to thank all regional blood centers across the country for their precious contribution and all technical staff who participated in this study.

\section{References}

[1] A. Benahadi, R. Alami, S. Boulahdid et al., "Distribution of ABO and Rhesus D blood antigens in Morocco," The Internet Journal of Biological Anthropology, vol. 6, no. 1, article 1425, 2013.

[2] R. N. Makroo, A. Bhatia, R. Gupta, and J. Phillip, "Prevalence of Rh, Duffy, Kell, Kidd \& MNSs blood group antigens in 
the Indian blood donor population," Indian Journal of Medical Research, vol. 137, no. 3, pp. 521-526, 2013.

[3] C. Flickinger, T. Petrone, and A. Church, "Review: American rare donor program," Immunohematology, vol. 20, no. 4, pp. 239-243, 2004.

[4] A. E. Mourant, A.C. Kopec, and K. Domaniewska-Sobczak, The Distribution of the Human Blood Groups and Other Polymorphisms, Oxford University Press, London, UK, 1976.

[5] Ø. Hammer, D. A. T. Harper, and P. D. Ryan, "PAST: paleontological statistics software package for education and data analysis," Palaeontologia Electronica, vol. 4, no. 1, article 4, 9 pages, 2001, http://palaeo-electronica.org/2001_1/past/issue1_01.htm.

[6] Z. A. Jeremiah and C. Odumody, "Rh antigens and phenotype frequencies of the Ibibio, Efik, and Ibo ethnic nationalities in Calabar, Nigeria," Immunohematology, vol. 21, no. 1, pp. 21-24, 2005.

[7] B. M’Baya, T. Mfune, E. Mogombo, A. Mphalalo, D. Ndhlovu, and R. C. Knight, "The prevalence of red cell antigens and antibodies in Malawi," Transfusion Medicine, vol. 20, no. 3, pp. 196-199, 2010.

[8] F. F. Wagner, D. Kasulke, M. Kerowgan, and W. A. Flegel, "Frequencies of the blood groups ABO, Rhesus, D category VI, Kell, and of clinical relevant high-frequency antigens in SouthWestern Germany," Infusionstherapie und Transfusionsmedizin, vol. 22, no. 5, pp. 285-290, 1995.

[9] C. T. Tagny, S. Owusu-Ofori, D. Mbanya, and V. Deneys, "The blood donor in sub-Saharan Africa: a review," Transfusion Medicine, vol. 20, no. 1, pp. 1-10, 2010.

[10] H. Aireche, A. Gueguen, J. L. Golmard, and M. Benabadji, "Determination of gene frequencies in the Rhesus in Algeria system," Revue Française de Transfusion et ImmunoHématologie, vol. 25, no. 4, pp. 383-387, 1982.

[11] S. Hmida, F. Karrat, N. Mojaat, R. Dahri, and K. Boukef, "Rh system polymorphism in Tunisian population," Revue Francaise de Transfusion et d'Hémobiologie, vol. 36, no. 2, pp. 191-196, 1993.

[12] C. T. Hamed, M. A. Bollahi, I. Abdelhamid et al., "Distribution of RH and Kell blood group frequencies in the Mauritanian population," Blood Transfusion, vol. 11, pp. 154-155, 2013.

[13] D. M. Langhi Jr. and J. O. Bordin, "Duffy blood group and malaria," Hematology, vol. 11, no. 5-6, pp. 389-398, 2006.

[14] J. J. Lefrêre and P. Rouger, Pratique Nouvelle de la Transfusion Sanguine, Elsevier Masson, 2nd edition, 2006.

[15] R. R. Race and R. Sanger, Blood Group in Man, Blackwell Scientific Publications, Oxford, UK, 6th edition, 1975.

[16] M. Reid and C. Lomas-Francis, The Blood Group Antigen Facts Book, Elsevier Academic Press, New York, NY, USA, 2nd edition, 2004. 


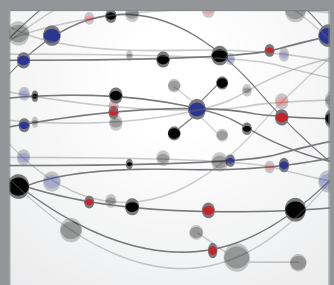

The Scientific World Journal
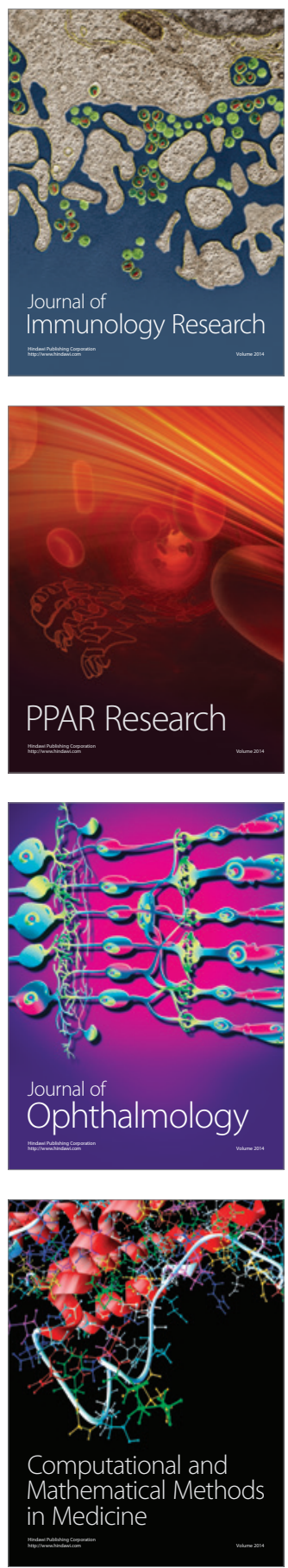

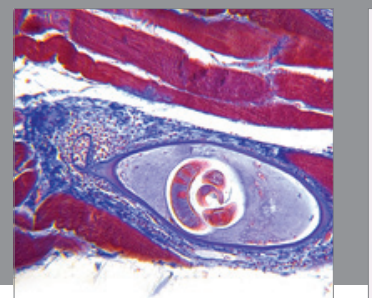

Gastroenterology

Research and Practice
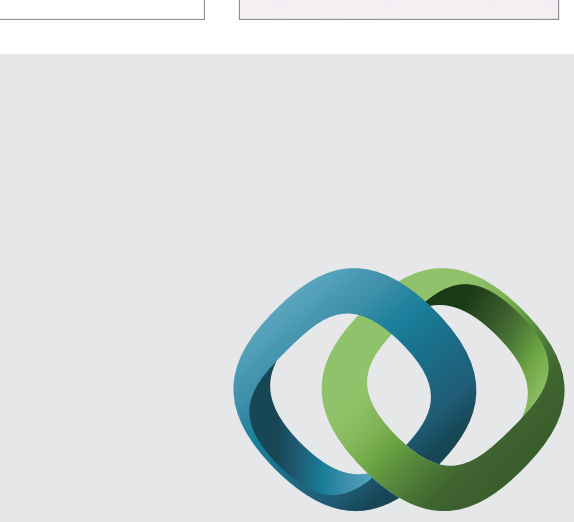

\section{Hindawi}

Submit your manuscripts at

http://www.hindawi.com
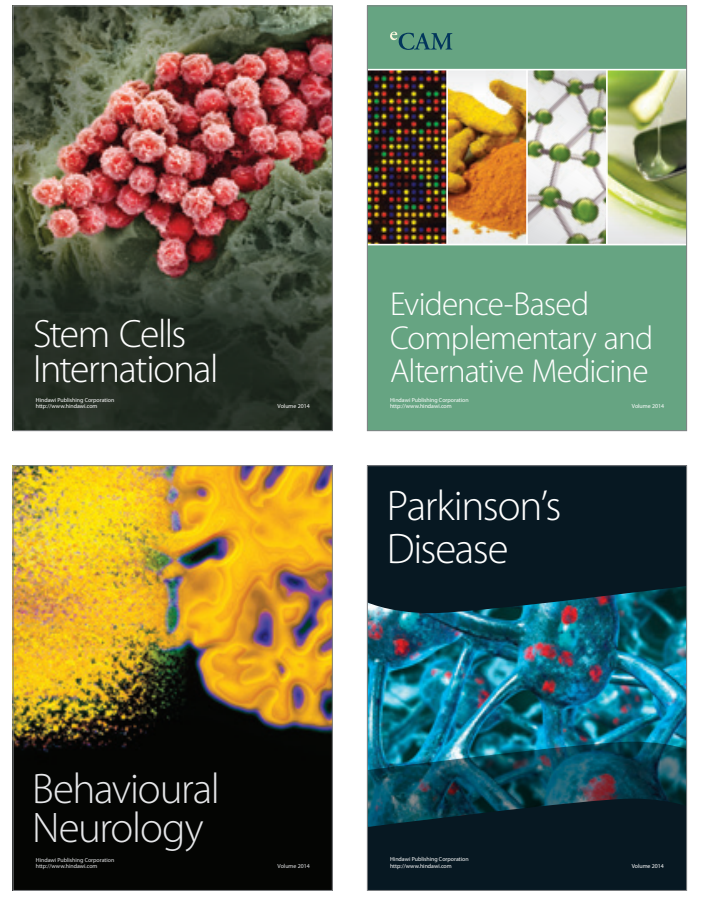
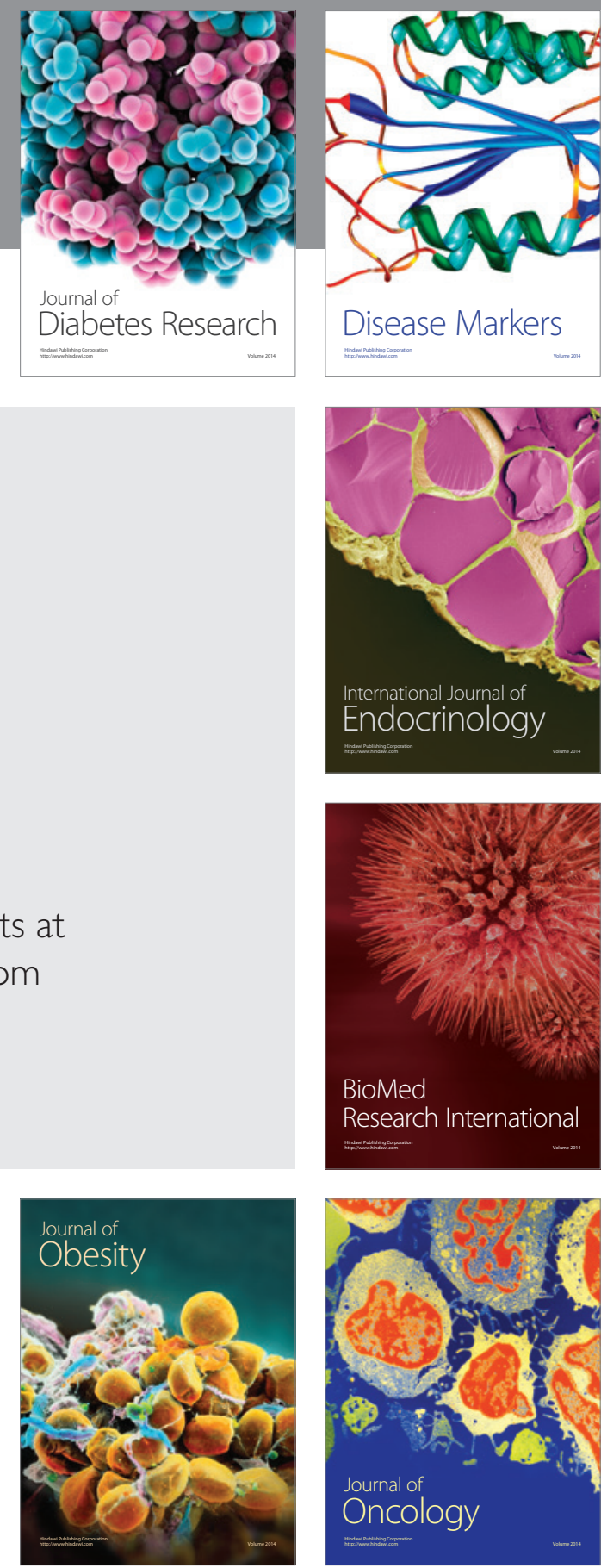

Disease Markers
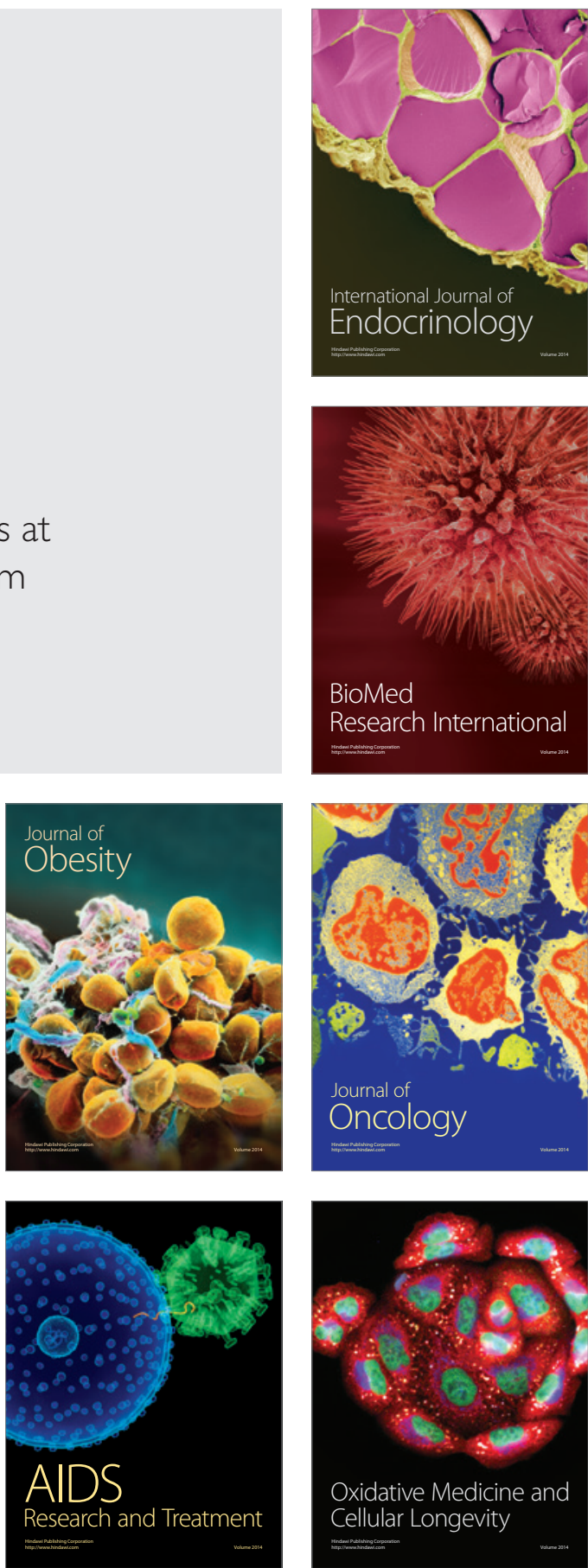